\title{
Review
}

Ophthalmic

Research

Ophthalmic Res 2014;51:88-95

DOI: $\underline{10.1159 / 000356693}$
Received: September 16, 2013

Accepted after revision: October 10, 2013

Published online: December 12, 2013

\section{Pharmacological Approach to Diabetic Macular Edema}

\author{
F. Bandello ${ }^{a} \quad$ G. Casalino ${ }^{a} \quad$ A. Loewenstein ${ }^{b} \quad$ M. Goldstein ${ }^{b} \quad$ D. Pelayes ${ }^{c}$ \\ M. Battaglia Parodi ${ }^{a}$ \\ aDepartment of Ophthalmology, San Raffaele Scientific Institute, Vita-Salute University, Milan, Italy; \\ ${ }^{b}$ Department of Ophthalmology, Tel Aviv Medical Center, Sackler Faculty of Medicine, Tel Aviv University,

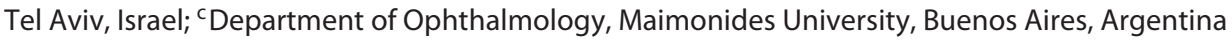

\section{Key Words}

Diabetic macular edema - Anti-vascular endothelial growth factor · Corticosteroids

\begin{abstract}
Diabetic macular edema (DME) is a highly prevalent cause of vision loss and has a remarkable impact on public health, and on the quality of life of diabetic patients. Even though laser photocoagulation has been the standard of care for decades, a substantial group of patients are unresponsive and fail to improve after laser treatment. Recently, new pharmacological approaches based on the use of intravitreal drugs, such as corticosteroids and anti-vascular endothelial growth factor, have revolutionized the treatment of DME. The use of intravitreal drugs is supported by the improvement in visual acuity reported by several clinical trials and can limit the potentially destructive effects of the laser treatment. Encouraging results also emerged from studies evaluating the use of a combination therapy, or the association of intravitreal drugs and laser treatment. This review aims at providing a brief synopsis of the main investigations regarding the current pharmacological approach to DME.
\end{abstract}

C 2013 S. Karger AG, Basel
() 2013 S. Karger AG, Basel

0030-3747/13/0512-0088\$38.00/0

\section{Introduction}

Diabetic macular edema (DME) is a highly prevalent cause of vision loss and has a remarkable impact on public health, and on the quality of life of diabetic patients. Even though systemic risk factors and glycemic control optimization remain the first-line treatment $[1,2]$, they are often insufficient in controlling the DME evolution. The Early Treatment of Diabetic Retinopathy Study (ETDRS) showed that focal/grid laser retinal photocoagulation reduced the risk of moderate visual loss by approximately $50 \%$ at 3 years [3]; thus, laser treatment has been considered the standard of care for the management of DME. However, a substantial group of patients are unresponsive and fail to improve after laser photocoagulation [4].

Recently, the improved knowledge of the molecular mechanisms of DME has led to new pharmacological approaches based on the use of intravitreal drugs, such as corticosteroids and anti-vascular endothelial growth factor (anti-VEGF). Encouraging results emerged also from studies evaluating the use of a combination therapy, or the association of intravitreal drugs and laser treatment. However, DME-specific characteristics appear paramount in the choice of the best therapeutic approach [5].

This review aims at providing a brief synopsis of the main investigations regarding the current pharmacological approach to DME.

\section{KARGER}

E-Mail karger@karger.com

www.karger.com/ore
Francesco Bandello, MD, FEBO

Department of Ophthalmology, San Raffaele Scientific Institute Vita-Salute University

Via Olgettina, 60, IT-20132 Milan (Italy)

E-Mail bandello.francesco@ hsr.it 


\section{Corticosteroids}

Due to the anti-inflammatory, angiostatic and antipermeability properties, corticosteroids have gained great interest in the treatment of DME. Although the exact mechanism of action is not fully understood, corticosteroids have been shown to interfere with the modulation of cytokines and growth factor production, leading to the stabilization of the blood-retina barrier with consequent reduction of the vascular permeability $[6,7]$. Several studies showed favorable responses to the treatment in terms of visual acuity recovery and DME resolution. However, relevant side effects are intraocular pressure increase and progression of cataract [8-11].

Currently, several formulations of steroids exist, with different durations of action, which may vary from nearly a month to 3 years [12].

\section{Triamcinolone Acetonide}

Intravitreal triamcinolone acetonide (IVTA) has been used for the treatment of DME in several clinical trials, showing improvement in morphological and functional outcomes [13-15], with a dose-dependent duration of its effect (about 6-9 months for a dose of about $20 \mathrm{mg}$, and about 2-4 months for a dose of $4 \mathrm{mg}$ ) [16].

The results of a 5-year randomized clinical trial (RCT) demonstrated that a visual improvement (defined as 5 or more letters gained) could be achieved in $42 \%$ of eyes treated with IVTA, compared to $32 \%$ of the placebo group [17].

The Diabetic Retinopathy Clinical Research Network (DRCR.net) in an RCT investigated the efficacy and safety of 1-and 4-mg doses of IVTA in comparison with focal or grid laser photocoagulation [18]. Analyses at 3 years showed that photocoagulation was more effective over time and had fewer side effects. Moreover a greater incidence of cataract progression and intraocular pressure increase was observed in the 4-mg triamcinolone group compared to the other groups [8].

In 2010, the DRCR.net published the results of a comparative RCT (DRCR.net protocol I) evaluating the efficacy of 3 different treatments for center-involved DME, including intravitreal ranibizumab (IVR) injection (0.5 $\mathrm{mg}$ ) combined with prompt or deferred ( $\geq 24$ weeks) laser, IVTA $(0.4 \mathrm{mg})$ combined with prompt laser, compared to sham injection combined with prompt laser alone [9]. Even though IVR with prompt or deferred laser was shown to be more effective than the other treatment modalities, in a subset of pseudophakic eyes IVTA com-

Pharmacological Approach to Diabetic Macular Edema bined with prompt laser achieved results similar to IVR and was more effective than laser alone, but the risk of intraocular pressure elevation was increased $[9,10]$. For these reasons, currently IVTA may be considered in pseudophakic eyes and in carefully selected patients of advanced DME who are refractory to laser or other interventions.

\section{Sustained Drug Delivery Systems}

The rationale in the use of slow-release intravitreal devices is in decreasing the number of intravitreal injections required coupled with a sustained concentration of the drug in the vitreous cavity. These two features of the sustained drug delivery systems lead to a decrease in the number of injection-associated adverse events.

\section{Dexamethasone}

Dexamethasone (DEX) is a powerful corticosteroid and plays an active role in the reduction of inflammatory mediators implicated in DME [19]. DEX can be delivered to the back of the eye via a sustained-release intravitreal implant (DEX implant 0.7 mg; Ozurdex; Allergan Inc., Irvine, Calif., USA) that is placed through a small pars plana incision using a customized applicator system and slowly releases the drug for up to 6 months $[20,21]$.

In 171 eyes with persistent macular edema ( $\geq 3$ months of duration) Haller et al. [22] compared 2 doses of DEX (350 and $700 \mu \mathrm{m}$ ) to observation.

At 90 days, the $700-\mu \mathrm{m}$ group showed a statistically significantly higher proportion of patients with a gain of 10 or more letters compared with the observation group (33 vs. $12 \%)$. Nonstatistically significant improvement was observed for the 350- $\mu \mathrm{m}$ group compared with the observation group ( 21 vs. $12 \%$ ). At 180 days, there was no statistically significant difference between either the DEX group or no-treatment group. The treatment effect appeared to peak at 3 months. In a recent retrospective study evaluating the effects of intravitreal DEX implantation in 9 patients with persistent DME, an improvement in bestcorrected visual acuity (BCVA) was seen as soon as the first days after the injection and was maintained until the fourth month [23]. Moreover results of a study conducted by Boyer et al. [24] showed that DEX implantation was effective also in vitrectomized eyes affected by DME.

\section{Fluocinolone Acetonide}

Recently, 2 nonbiodegradable fluocinolone acetonide (FA) sustained-delivery devices have been developed 
(Iluvien ${ }^{\circledR}$, Alimera Sciences, Alpharetta, Ga., and Retisert ${ }^{\circledR}$, Bausch \& Lomb, Rochester, N.Y., USA) to provide substantial benefit in patients with DME for up to 3 years. These implants can be inserted in the vitreous cavity through a 25 -gauge needle.

The FAME Study Group assessed the long-term efficacy and safety of intravitreal inserts releasing $0.2 \mu \mathrm{g} / \mathrm{day}$ (low dose) or $0.5 \mu \mathrm{g} /$ day (high dose) FA versus a sham injection [11].

Rescue laser was given after the first 6 weeks for persistent DME and was allowed every 3 months; $35-37 \%$ of patients in the FA group and 59\% in the sham injection group required rescue laser. At 24 months, both doses of FA showed a statistically significant improvement in mean BCVA compared to sham treatment. There was a modest difference between FA groups. An extended follow-up at 36 months [25] showed that both FA arms continued to result in a statistically significant benefit compared to the sham group. However, high rates of intraocular pressure rise and cataract surgery were frequently registered in all groups receiving corticosteroids.

Almost all phakic patients in the FA insert groups developed cataract $(88.7$ and $81.7 \%$ for the low- and highdose insert groups, respectively, compared to the $50.7 \%$ of untreated groups) even if, after cataract surgery, the visual benefit was similar to that in pseudophakic eyes. The incidence of glaucoma requiring incisional surgery was 8.1 and $4.8 \%$ in the low- and high-dose groups, respectively.

Pearson et al. [26] compared fluocinolone $(0.59 \mathrm{mg})$ with standard of care, either laser or no treatment, in 196 patients with refractory DME. At 3 years, there was no statistically significant difference in the proportion of patients with a 15 -letter gain or more (31\% fluocinolone compared with $20 \%$ standard of care) between groups as well as the proportion of patients losing 15 letters or more (17\% fluocinolone compared with $14 \%$ standard of care). An increased incidence of cataracts in the fluocinolone group may have contributed to this difference.

\section{Anti-VEGF Therapy}

Anti-VEGF therapy has revolutionized the treatment of DME. VEGF plays a critical role in promoting angiogenesis and vascular leakage [27], and several different anti-VEGF drugs have been studied in the management of DME, including ranibizumab, bevacizumab, pegaptanib and, more recently, aflibercept $[28,29]$. They exhibit important differences in their sites of activity, formulation methods, binding affinities and biological activities.

\section{Ranibizumab}

Ranibizumab (Lucentis; Genentech USA Inc., San Francisco, Calif., USA/Novartis Ophthalmics, Basel, Switzerland) is an engineered, humanized, recombinant antibody fragment (Fab, or antigen-binding fragment) active against all VEGF-A isoforms [30]. A beneficial effect of IVR in DME has been shown by several RCTs. Two phase II studies (RESOLVE and READ-2) and two phase III studies (RESTORE and DRCR.net protocol I) compared the effect of ranibizumab with sham (RESOLVE and RESTORE) or with laser photocoagulation and triamcinolone (READ-2 and DRCR.net protocol I).

The RESOLVE $(\mathrm{n}=151)$ study investigated IVR as monotherapy for DME, comparing patients receiving either 0.3 or $0.5 \mathrm{mg}$ IVR with those receiving sham treatment only [31]. At month 12, data showed a mean BCVA gain of 10.3 letters in the IVR group compared with a loss of 1.4 letters in the sham treatment group. Only $4.9 \%$ of the patients receiving IVR required rescue laser compared with $34.7 \%$ of those receiving sham treatment. No differences were found in the rates of ocular and nonocular adverse events or serious adverse events between the two treatment groups.

The READ-2 study showed better visual acuity in eyes treated with IVR versus eyes treated with photocoagulation [32]. In this study 126 patients were randomized into 3 arms: in the first group, IVR $(0.5 \mathrm{mg})$ was administered at baseline and months 1, 3 and 5; in the second group, laser was performed at baseline and month 3 if needed, and the third group was treated with a combination of IVR $(0.5 \mathrm{mg})$ and macular laser at baseline and month 3. At month 6, the mean improvement in BCVA was significantly greater in the IVR group compared with the laser group with no statistical difference between the monotherapy IVR $0.5 \mathrm{mg}$ and the combination group. The 2-year follow-up results further demonstrated that ranibizumab pro re nata was effective in maintaining the gained BCVA, showing mean BCVA improvements of 7.7 letters (IVR-only group), 5.1 letters (laser group) and 6.8 letters (combination therapy group) in the 101 patients who remained in the study [33]. Afterwards, only the patients who agreed to continue the study (in the ranibizumab group, 28 patients; in laser, 22; in ranibizumab + laser, 24) returned monthly and received ranibizumab pro re nata. At month 36 BCVA improvement in the ranibizumab group was 10.3 letters compared with 7.2 letters at month 24 whereas no statistically significant improvement was found for the laser and laser + ranibizumab groups.
90

Ophthalmic Res 2014;51:88-95 DOI: $10.1159 / 000356693$
Bandello/Casalino/Loewenstein/ Goldstein/Pelayes/Battaglia Parodi 
However, edema resolution occurred more in the laser and ranibizumab + laser groups [34].

The RESTORE study included 345 patients with focal or diffuse DME receiving IVR monotherapy, laser monotherapy or IVR combined with laser. At 1 year, the study showed a larger mean BCVA improvement in patients treated with IVR monotherapy or IVR combined with laser than in patients treated with laser alone. No differences were detected between the IVR monotherapy and IVR + laser arms [35]. In the 2-year extension of the study ranibizumab was given pro re nata, and visual gain was maintained with fewer ranibizumab injections in the IVR group [36].

The DRCR.net protocol I $(n=691)$ assessed whether IVR, combined with either prompt (within 10 days) or deferred (no sooner than 6 months) laser, or IVTA combined with prompt laser, might result in improved visual acuity outcomes in comparison with the gold standard of focal/grid photocoagulation for DME involving the central macula [9]. The results at 1 and 2 years led to similar conclusions showing that IVR $0.5 \mathrm{mg}$ in combination with prompt or deferred laser improved visual acuity more than laser photocoagulation alone (and than IVTA combined with laser) $[9,10]$.

Recently, in 2 parallel, phase III RCTs, RISE $(n=377)$ and RIDE $(\mathrm{n}=382)$ [37], IVR has been evaluated in the treatment of DME compared with placebo again. These trials followed identical protocols, through 2 parallel, phase III, multicenter studies, comparing monthly injections of $0.3 \mathrm{mg}$ IVR or $0.5 \mathrm{mg}$ IVR with sham injection for 24 months. At 24 months, in the RISE group, $44.8 \%$ of $0.3-\mathrm{mg}$ patients and $39.2 \%$ of $0.5-\mathrm{mg}$ IVR patients gained $\geq 15$ letters, compared to $18.1 \%$ of sham patients, while in the RIDE group, $33.6 \%$ of $0.3-\mathrm{mg}$ patients and $45.7 \%$ of 0.5 -mg IVR patients gained $\geq 15$ letters, compared to $12.3 \%$ of sham patients. In the third year, the study design allowed for patients in the sham group to cross over and receive monthly ranibizumab injections. The 36-month outcomes were recently published and confirmed the long-term efficacy and safety of ranibizumab in DME. However, delayed treatment in patients receiving sham treatment initially did not seem to result in the same functional gain observed in patients originally randomized to ranibizumab [38].

Data from an exploratory analysis of the DRCR.net trial evaluating the effect on worsening of diabetic retinopathy of IVR and IVTA in comparison with sham + prompt laser have recently been published [39]. The results showed that IVR is associated with a reduced risk of diabetic retinopathy worsening in eyes with or without

Pharmacological Approach to Diabetic Macular Edema proliferative diabetic retinopathy. More specifically, for eyes without proliferative diabetic retinopathy at baseline, the 3-year cumulative probabilities for retinopathy worsening were $23 \%$ using sham with prompt laser, $18 \%$ with IVR with prompt laser, $7 \%$ with IVR with deferred laser and 37\% with IVT with prompt laser. For eyes with proliferative diabetic retinopathy at baseline, the 3-year cumulative probabilities for retinopathy worsening were $40,21,18$ and $12 \%$, respectively.

Recently, a review of an expert panel [40] established new approaches and recommendations for the treatment of DME with ranibizumab. DME with or without visual impairment should be considered for treatment when the ETDRS criteria for clinically significant macular edema $[3,41]$ are respected. For DME with center involvement and vision loss due to DME, monthly ranibizumab monotherapy is recommended with treatment interruption and re-initiation based on visual acuity stability. For other types of clinically significant DME with no vision loss or without center involvement, laser treatment based on ETDRS guidelines is recommended.

\section{Bevacizumab}

Bevacizumab (Avastin; Genentech Inc., San Francisco, Calif., USA) is a full-length recombinant humanized antibody active against all isoforms of VEGF-A.

The use of intravitreal bevacizumab (IVB) to treat DME was first considered by the DRCR.net in a large phase II RCT [42]. A higher improvement in BCVA which was sustained up to 12 weeks was found in the IVB monotherapy group compared to the group who was treated with focal laser photocoagulation at baseline. A longer-term follow-up was reported by Arevalo et al. and the PACORES group [43], showing the visual acuity gain was preserved for up to 24 months. Later, Lam et al. [44] evaluated the efficacy of 2 doses of IVB ( 1.25 and $2.5 \mathrm{mg}$ ) in a small trial with a 6-month follow-up. The results showed that the 2 doses of IVB were similarly effective in improving BCVA. In the same year in a retrospective case series, Kook et al. [45] reported that a successful treatment with repeated IVB injections could be achieved over a 24-month follow-up period even in cases of chronic ischemic DME.

In an RCT, Soheilian et al. [46, 47] compared combined IVB (1.25 mg) + IVTA ( $2 \mathrm{mg})$ with IVB alone and laser alone in 97 patients who were laser naïve. At 36 weeks, IVB alone improved BCVA more than either combination therapy or laser, although the difference was not 
statistically significant. An extended follow-up at 24 months showed that there was no statistically significant difference between groups for BCVA. However, there was a trend in favor of the bevacizumab and combination arms more than in the laser one [48]. Moreover IVB alone turned out to be superior to IVB + IVTA and macular laser photocoagulation only in eyes with an initial central macular thickness of $\geq 350 \mu \mathrm{m}$, indicating that in the primary treatment of DME the initial central macular thickness may be an important factor in decision making.

Recently, the results of a prospective RCT (BOLT study), comparing IVB versus laser in persistent DME in 80 patients, were published [49]. The 2-year results showed that the mean gain in ETDRS letters was 9 and 2.5 letters in the IVB and laser groups, respectively; an improvement of 10 or more letters was seen in the 45 and $7 \%$ of the two arms, respectively [50]. A post hoc analysis of the BOLT study aimed to explore the parameters that influence the injection frequency in the patients randomized in the IVB arm [51]. Results showed that the only determinant of fewer injections in the second year was a better baseline visual acuity. Moreover eyes with subretinal detachment required more injections than diffuse and cystoid edema.

However, there is a diffuse concern among clinicians about an increase in major cardiovascular events using bevacizumab. As underlined by a recent meta-analysis by Goyal et al. [52], few data are available to rule out this possibility. Therefore we suggest to avoid bevacizumab in high-risk patients.

\section{Pegaptanib}

Pegaptanib sodium (Macugen, Eyetech Inc., Cedar Knolls, N.J., USA) is a ribonucleic acid aptamer that binds specifically to the VEGF-A165 isomer, the major pathological VEGF protein in the eye.

The Macugen Diabetic Retinopathy Study was a phase II RCT studying 3 doses of intravitreal pegaptanib versus sham injection [53]. At the final visit at week 36, the group of patients receiving pegaptanib $0.3 \mathrm{mg}$ had significantly superior results compared to the sham injection group, as measured by BCVA and central retinal thickness. Furthermore, fewer patients receiving pegaptanib required retinal photocoagulation. Higher doses of pegaptanib (1 or $3 \mathrm{mg}$ ) did not show a significant improvement.

The Macugen Study [54] was a phase II/III RCT that compared pegaptanib with sham in 260 patients for 1 year and 207 patients for 2 years of follow-up. The authors stated an improvement of visual acuity $\geq 10$ ETDRS letters in week 54 in $36.8 \%$ of subjects in the pegaptanib sodium group and in $19.7 \%$ of the sham group compared with baseline values. A better visual acuity in the pegaptanib group was also reported at the end of the 2-year follow-up period. Moreover, fewer pegaptanib-treated subjects received laser treatment compared to shamtreated subjects.

\section{Aflibercept}

Aflibercept (VEGF Trap-Eye, Eylea, Regeneron/Bayer) is a soluble decoy receptor produced by fusing protein of portions of VEGF receptor 1 and 2 and the Fc region of human IgG. It binds all VEGF-A isoforms with higher affinity in comparison to all the other anti-VEGF substances. Moreover it has a longer half-life in the eye after intraocular injection and binds other members of the VEGF family as well, including placental growth factors 1 and 2 that have been shown to determine excessive vascular permeability. Thanks to these features, aflibercept achieved the same results as ranibizumab in neovascular age-related macular degeneration treatment, having also a longer duration of action [55]. The Da Vinci Study ( $\mathrm{n}=$ 221) is a randomized, double-masked, phase II clinical trial designed to compare the different doses and dosing regimens of the drug in DME $[56,57]$. Subjects were randomized to 1 of 5 arms: VEGF Trap-Eye 0.5 mg every 4 weeks; $2 \mathrm{mg}$ every 4 weeks; $2 \mathrm{mg}$ every 8 weeks after 3 initial monthly doses, or 2-mg dosing as needed after 3 initial monthly doses, or macular laser photocoagulation. A significant improvement in BCVA was achieved at week 24 and was maintained or enhanced at week 52 in all aflibercept arms. Recently aflibercept was approved by the European Union for neovascular age-related macular degeneration and central retinal vein occlusion treatment and by the Food and Drug Administration for extension to DME patients.

\section{Combined Therapy}

The combination of pharmacological therapy with focal laser photocoagulation has the potential to improve the efficacy of treatment for DME, reducing the burden of frequent intravitreal injections.

The RESTORE study showed a larger mean BCVA improvement in patients treated with a combination of IVR and laser than in patients treated with laser alone [35].
92

Ophthalmic Res 2014;51:88-95 DOI: $10.1159 / 000356693$
Bandello/Casalino/Loewenstein/ Goldstein/Pelayes/Battaglia Parodi 
Conversely, in the READ 2 study there was no statistical difference for the combination group. However, the combination treatment with IVR + laser provided an improvement in BCVA and a greater decrease in macular edema, with a reduced number of intravitreal injections [33].

DRCR.net protocol I extended the follow-up only for eyes originally assigned to ranibizumab + prompt or deferred laser treatment [58]. Three-year follow-up results suggested that adding prompt laser treatment to IVR is no better and possibly worse for visual outcome than deferring laser for at least 24 weeks. The authors stated that some of the observed differences in visual acuity may be related to the lower number of injections during the follow-up in the prompt laser treatment group.

Also intravitreal steroids can play an important role as a part of combination treatment [59]. In a 2-year study recently reported by Gillies et al. [60], eyes with DME treated with IVTA + laser were twice as likely as eyes treated with laser alone to achieve at least a 10-letter improvement in BCVA from baseline at year 2. A recent study conducted by Lim et al. [61] compared bevacizumab alone, bevacizumab combined with triamcinolone and triamcinolone alone. After 12 months of follow-up, BCVA was comparable between the 3 study groups. Recently, the Ozurdex PLACID Study Group [62] evaluated a DEX intravitreal implant $0.7 \mathrm{mg}$ combined with laser photocoagulation compared with laser alone for the treatment of diffuse DME. Up to month 9 significantly greater improvement in BCVA occurred in patients treated with the DEX implant + laser than in patients treated with laser alone. However, at month 12 there was no significant difference between groups.

\section{Other Drugs}

PF-04523655 is a short interfering RNA targeting the expression of a gene involved in increasing vascular permeability. RTP-801 gene showed a dose-related tendency for improvement in BCVA in DME patients [63].

Bevasiranib is a small interfering RNA molecule able to inactivate messenger RNA and to suppress RNA translation. It is designed to reduce the levels and activity of VEGF messenger RNA. In a phase II RCT, 48 eyes were treated with 3 monthly injections and followed for 1 additional month. There was no statistically significant change in macular thickness (the primary end point) or mean visual acuity at the 4-month time point [64].

Sirolimus, or rapamycin, is a macrocyclic antibiotic (produced by Streptomyces hygroscopicus) that binds spe- cifically FKBP12; the active complex inhibits the mammalian target of rapamycin, a kinase which integrates growth factor-activated signals including signals that promote angiogenesis mediated by VEGF. Besides, mammalian target of rapamycin is an activator of VEGF gene transcription via the hypoxia-inducible factor 1a. Phase I/II study data showed the safety of subconjunctival and intravitreal injections of sirolimus in patients with DME $[65,66]$.

\section{Conclusions}

With the advent of intravitreal drugs, a new era was opened for the pharmacological approach to DME. Even though laser treatment is still applied, the use of intravitreal drugs is supported by encouraging results regarding improvement in visual acuity, and it can limit the potentially destructive effects of the laser treatment. However, the best frequency and dosing regimen of intravitreal drugs are not yet clearly defined. Moreover a longer follow-up is required to investigate the long-term results and the safety profile. To date, downsides of intravitreal injections appear to be: the relatively short half-life, and the need for repeated injections to obtain and maintain the desired therapeutic effects, producing an increased risk of injection-related complications, even though those risks are small. In light of this the combination therapy is a promising option to be better investigated. However, the best therapeutic approach to DME should be specifically defined on the basis of disease characteristics in the individual patient. Lastly, an important goal will be an improvement in the understanding of DME pathogenesis in order to study new selective molecules.

\section{Disclosure Statement}

The authors have no proprietary interest in the materials used in this study.

References

Ophthalmic Res 2014;51:88-95

1 The effect of intensive treatment of diabetes on the development and progression of longterm complications in insulin-dependent diabetes mellitus. The Diabetes Control and Complications Trial Research Group. N Engl J Med 1993;329:977-986.

-2 Effect of intensive blood-glucose control with metformin on complications in overweight patients with type 2 diabetes (UKPDS 34). UK Prospective Diabetes Study (UKPDS) Group. Lancet 1998;352:854-865. 
-3 Early Treatment Diabetic Retinopathy Study research group: Photocoagulation for diabetic macular edema. Early Treatment Diabetic Retinopathy Study report No 1. Arch Ophthalmol 1985;103:1796-1806.

4 Lee CM, Olk RJ: Modified grid laser photocoagulation for diffuse diabetic macular edema. Long-term visual results. Ophthalmology 1991;98:1594-1602.

5 Bandello F, Battaglia Parodi M, Lanzetta P, 18 Loewenstein A, Massin P, Menchini F, et al: Diabetic macular edema. Dev Ophthalmol 2010;47:73-110.

-6 Antonetti DA, Wolpert EB, DeMaio L, Harhaj NS, Scaduto RC Jr: Hydrocortisone decreases retinal endothelial cell water and solute flux coincident with increased content and decreased phosphorylation of occludin. J Neurochem 2002;80:667-677.

7 Wang J, Xu X, Elliott MH, Zhu M, Le YZ: Muller cell-derived VEGF is essential for diabetes-induced retinal inflammation and vascular leakage. Diabetes 2010;59:2297-2305.

-8 Beck RW, Edwards AR, Aiello LP, Bressler NM, Ferris F, Glassman AR, et al: Three-year follow-up of a randomized trial comparing focal/grid photocoagulation and intravitreal triamcinolone for diabetic macular edema. Arch Ophthalmol 2009;127:245-251.

>9 Elman MJ, Aiello LP, Beck RW, Bressler NM, Bressler SB, Edwards AR, et al: Randomized trial evaluating ranibizumab plus prompt or deferred laser or triamcinolone plus prompt laser for diabetic macular edema. Ophthalmology 2010;117:1064-1077.

- 10 Elman MJ, Bressler NM, Qin H, Beck RW, Ferris FL 3rd, Friedman SM, et al: Expanded 2-year follow-up of ranibizumab plus prompt or deferred laser or triamcinolone plus prompt laser for diabetic macular edema. Ophthalmology 2011;118:609-614.

- 11 Campochiaro PA, Brown DM, Pearson A, Ciulla T, Boyer D, Holz FG, et al: Long-term benefit of sustained-delivery fluocinolone acetonide vitreous inserts for diabetic macular edema. Ophthalmology 2011;118:626-635.

-12 Lee SS, Hughes PM, Robinson MR: Recent advances in drug delivery systems for treating ocular complications of systemic diseases. Curr Opin Ophthalmol 2009;20:511-519.

-13 Audren F, Erginay A, Haouchine B, Benosman R, Conrath J, Bergmann JF, et al: Intravitreal triamcinolone acetonide for diffuse diabetic macular oedema: 6-month results of a prospective controlled trial. Acta Ophthalmol Scand 2006;84:624-630.

14 Gillies MC, Sutter FK, Simpson JM, Larsson J, Ali $\mathrm{H}$, Zhu M: Intravitreal triamcinolone for refractory diabetic macular edema: two-year results of a double-masked, placebo-controlled, randomized clinical trial. Ophthalmology 2006;113:1533-1558.

-15 Jonas JB, Kamppeter BA, Harder B, Vossmerbaeumer U, Sauder G, Spandau UH: Intravitreal triamcinolone acetonide for diabetic macular edema: a prospective, randomized study. J Ocul Pharmacol Ther 2006;22:200-207.
16 Jonas JB: Intravitreal triamcinolone acetonide: a change in a paradigm. Ophthalmic Res 2006;38:218-245

17 Gillies MC, Simpson JM, Gaston C, Hunt G, Ali H, Zhu M, et al: Five-year results of a randomized trial with open-label extension of triamcinolone acetonide for refractory diabetic macular edema. Ophthalmology 2009;116: 2182-2187.

18 A randomized trial comparing intravitreal triamcinolone acetonide and focal/grid photocoagulation for diabetic macular edema. Ophthalmology 2008;115:1447-1449. e1e10.

19 Funatsu H, Noma H, Mimura T, Eguchi S, Hori S: Association of vitreous inflammatory factors with diabetic macular edema. Ophthalmology 2009;116:73-79.

20 Haller JA, Dugel P, Weinberg DV, Chou C, Whitcup SM: Evaluation of the safety and performance of an applicator for a novel intravitreal dexamethasone drug delivery system for the treatment of macular edema. Retina 2009;29:46-51.

21 Chang-Lin JE, Attar M, Acheampong AA, Robinson MR, Whitcup SM, Kuppermann $\mathrm{BD}$, et al: Pharmacokinetics and pharmacodynamics of a sustained-release dexamethasone intravitreal implant. Invest Ophthalmol Vis Sci 2011;52:80-86.

22 Haller JA, Kuppermann BD, Blumenkranz MS, Williams GA, Weinberg DV, Chou C, et al: Randomized controlled trial of an intravitreous dexamethasone drug delivery system in patients with diabetic macular edema. Arch Ophthalmol 2010;128:289-296.

23 Zucchiatti I, Lattanzio R, Querques G, Querques L, Del Turco C, Cascavilla ML, et al: Intravitreal dexamethasone implant in patients with persistent diabetic macular edema. Ophthalmologica 2012;228:117-122.

24 Boyer DS, Faber D, Gupta S, Patel SS, Tabandeh H, Li XY, et al: Dexamethasone intravitreal implant for treatment of diabetic macular edema in vitrectomized patients. Retina 2011; 31:915-923.

25 Campochiaro PA, Brown DM, Pearson A Chen S, Boyer D, Ruiz-Moreno J, et al: Sustained delivery fluocinolone acetonide vitreous inserts provide benefit for at least 3 years in patients with diabetic macular edema. Ophthalmology 2012;119:2125-2132.

26 Pearson PA, Comstock TL, Ip M, Callanan D, Morse LS, Ashton P, et al: Fluocinolone acetonide intravitreal implant for diabetic macular edema: a 3-year multicenter, randomized, controlled clinical trial. Ophthalmology 2011; 118:1580-1587.

27 Nguyen QD, Tatlipinar S, Shah SM, Haller JA, Quinlan E, Sung J, et al: Vascular endothelial growth factor is a critical stimulus for diabetic macular edema. Am J Ophthalmol 2006; 142:961-969.

28 Iacono P, Battaglia Parodi M, Bandello F: Antivascular endothelial growth factor in diabetic retinopathy. Dev Ophthalmol 2010;46:3953.
29 Bandello F, Berchicci L, La Spina C, Battaglia Parodi M, Iacono P: Evidence for anti-VEGF treatment of diabetic macular edema. Ophthalmic Res 2012;48(suppl 1):16-20.

30 Ferrara N, Damico L, Shams N, Lowman H, Kim R: Development of ranibizumab, an antivascular endothelial growth factor antigen binding fragment, as therapy for neovascular age-related macular degeneration. Retina 2006;26:859-870.

31 Massin P, Bandello F, Garweg JG, Hansen LL, Harding SP, Larsen M, et al: Safety and efficacy of ranibizumab in diabetic macular edema (RESOLVE Study): a 12-month, randomized, controlled, double-masked, multicenter phase II study. Diabetes Care 2010;33:2399_ 2405.

-32 Nguyen QD, Shah SM, Heier JS, Do DV, Lim J, Boyer D, et al: Primary end point (six months) results of the Ranibizumab for Edema of the Macula in Diabetes (READ-2) study. Ophthalmology 2009;116:2175-2181.

-33 Nguyen QD, Shah SM, Khwaja AA, Channa R, Hatef E, Do DV, et al: Two-year outcomes of the Ranibizumab for Edema of the Macula in Diabetes (READ-2) study. Ophthalmology 2010;117:2146-2151.

34 Do DV, Nguyen QD, Khwaja AA, Channa R, Sepah YJ, Sophie R, et al: Ranibizumab for Edema of the Macula in Diabetes study: 3 -year outcomes and the need for prolonged frequent treatment. JAMA Ophthalmol 2013; 131:139-145.

-35 Mitchell P, Bandello F, Schmidt-Erfurth U, Lang GE, Massin P, Schlingemann RO, et al: The RESTORE study: ranibizumab monotherapy or combined with laser versus laser monotherapy for diabetic macular edema. Ophthalmology 2011;118:615-625.

- 36 Lang GE, Berta A, Eldem BM, Simader C, Sharp D, Holz FG, et al: Two-year safety and efficacy of ranibizumab $0.5 \mathrm{mg}$ in diabetic macular edema: interim analysis of the RESTORE extension study. Ophthalmology 2013;120:2004-2012.

- 37 Nguyen QD, Brown DM, Marcus DM, Boyer DS, Patel S, Feiner L, et al: Ranibizumab for diabetic macular edema: results from 2 phase III randomized trials: RISE and RIDE. Ophthalmology 2012;119:789-801.

- 38 Brown DM, Nguyen QD, Marcus DM, Boyer DS, Patel S, Feiner L, et al: Long-term outcomes of ranibizumab therapy for diabetic macular edema: the 36-month results from two phase III trials: RISE and RIDE. Ophthalmology 2013;120:2013-2022.

39 Bressler SB, Qin H, Melia M, Bressler NM, Beck RW, Chan CK, et al: Exploratory analysis of the effect of intravitreal ranibizumab or triamcinolone on worsening of diabetic retinopathy in a randomized clinical trial. JAMA Ophthalmol 2013;131:1033-1040.

-40 Bandello F, Cunha-Vaz J, Chong NV, Lang GE, Massin P, Mitchell P, et al: New approaches for the treatment of diabetic macular oedema: recommendations by an expert panel. Eye (Lond) 2012;26:485-493. 
41 Treatment techniques and clinical guidelines for photocoagulation of diabetic macular edema. Early Treatment Diabetic Retinopathy Study Report No 2. Early Treatment Diabetic Retinopathy Study Research Group. Ophthalmology 1987;94:761-774.

-42 Scott IU, Edwards AR, Beck RW, Bressler NM, Chan CK, Elman MJ, et al: A phase II randomized clinical trial of intravitreal bevacizumab for diabetic macular edema. Ophthalmology 2007;114:1860-1867.

-43 Arevalo JF, Sanchez JG, Wu L, Maia M, Alezzandrini AA, Brito M, et al: Primary intravitreal bevacizumab for diffuse diabetic macular edema: the Pan-American Collaborative Retina Study Group at 24 months. Ophthalmology 2009;116:1488-1497.

44 Lam DS, Lai TY, Lee VY, Chan CK, Liu DT, Mohamed S, et al: Efficacy of $1.25 \mathrm{mg}$ versus $2.5 \mathrm{mg}$ intravitreal bevacizumab for diabetic macular edema: six-month results of a randomized controlled trial. Retina 2009;29:292299.

-45 Kook D, Wolf A, Kreutzer T, Neubauer A, Strauss R, Ulbig M, et al: Long-term effect of intravitreal bevacizumab (Avastin) in patients with chronic diffuse diabetic macular edema. Retina 2008;28:1053-1060.

-46 Soheilian M, Ramezani A, Bijanzadeh B, Yaseri $\mathrm{M}$, Ahmadieh $\mathrm{H}$, Dehghan $\mathrm{MH}$, et al: Intravitreal bevacizumab (Avastin) injection alone or combined with triamcinolone versus macular photocoagulation as primary treatment of diabetic macular edema. Retina 2007; 27:1187-1195.

-47 Soheilian M, Ramezani A, Obudi A, Bijanzadeh B, Salehipour M, Yaseri M, et al: Randomized trial of intravitreal bevacizumab alone or combined with triamcinolone versus macular photocoagulation in diabetic macular edema. Ophthalmology 2009;116:1142-1150.

48 Soheilian M, Garfami KH, Ramezani A, Yaseri M, Peyman GA: Two-year results of a randomized trial of intravitreal bevacizumab alone or combined with triamcinolone versus laser in diabetic macular edema. Retina 2012;32:314-321
49 Michaelides M, Kaines A, Hamilton RD, Fraser-Bell S, Rajendram R, Quhill F, et al: A prospective randomized trial of intravitreal bevacizumab or laser therapy in the management of diabetic macular edema (BOLT study) 12-month data: report 2. Ophthalmology 2010;117:1078-1086.

50 Rajendram R, Fraser-Bell S, Kaines A, Michaelides M, Hamilton RD, Esposti SD, et al: A 2-year prospective randomized controlled trial of intravitreal bevacizumab or laser therapy (BOLT) in the management of diabetic macular edema 24-month data: report 3. Arch Ophthalmol 2012;130:972-979.

51 Sivaprasad S, Crosby-Nwaobi R, Heng LZ, Peto T, Michaelides M, Hykin P: Injection frequency and response to bevacizumab monotherapy for diabetic macular oedema (BOLT report 5). Br J Ophthalmol 2013;97:11771180 .

52 Goyal S, Lavalley M, Subramanian ML: Metaanalysis and review on the effect of bevacizumab in diabetic macular edema. Graefes Arch Clin Exp Ophthalmol 2011;249:15-27.

53 Cunningham ET Jr, Adamis AP, Altaweel M, Aiello LP, Bressler NM, D'Amico DJ, et al: A phase II randomized double-masked trial of pegaptanib, an anti-vascular endothelial growth factor aptamer, for diabetic macular edema. Ophthalmology 2005;112:1747-1757.

54 Sultan MB, Zhou D, Loftus J, Dombi T, Ice KS: A phase $2 / 3$, multicenter, randomized, double-masked, 2-year trial of pegaptanib sodium for the treatment of diabetic macular edema. Ophthalmology 2011;118:1107-1118.

- 55 Heier JS, Brown DM, Chong V, Korobelnik JF, Kaiser PK, Nguyen QD, et al: Intravitreal aflibercept (VEGF Trap-Eye) in wet age-related macular degeneration. Ophthalmology 2012;119:2537-2548.

56 Do DV, Schmidt-Erfurth U, Gonzalez VH, Gordon CM, Tolentino M, Berliner AJ, et al: The Da Vinci Study: phase 2 primary results of VEGF Trap-Eye in patients with diabetic macular edema. Ophthalmology 2011;118: 1819-1826.

57 Do DV, Nguyen QD, Boyer D, Schmidt-Erfurth U, Brown DM, Vitti R, et al: One-year outcomes of the Da Vinci Study of VEGF Trap-Eye in eyes with diabetic macular edema. Ophthalmology 2012;119:1658-1665.
58 Elman MJ, Qin H, Aiello LP, Beck RW, Bressler NM, Ferris FL 3rd, et al: Intravitreal ranibizumab for diabetic macular edema with prompt versus deferred laser treatment: three-year randomized trial results. Ophthalmology 2012;119:2312-2318.

-59 Bandello F, Battaglia Parodi M, Tremolada G, Lattanzio R, De Benedetto U, Iacono P: Steroids as part of combination treatment: the future for the management of macular edema? Ophthalmologica 2010;224(suppl 1):4145.

60 Gillies MC, McAllister IL, Zhu M, Wong W, Louis D, Arnold JJ, et al: Intravitreal triamcinolone prior to laser treatment of diabetic macular edema: 24-month results of a randomized controlled trial. Ophthalmology 2011;118:866-872.

61 Lim JW, Lee HK, Shin MC: Comparison of intravitreal bevacizumab alone or combined with triamcinolone versus triamcinolone in diabetic macular edema: a randomized clinical trial. Ophthalmologica 2012;227:100-106.

-62 Callanan DG, Gupta S, Boyer DS, Ciulla TA Singer MA, Kuppermann BD, et al: Dexamethasone intravitreal implant in combination with laser photocoagulation for the treatment of diffuse diabetic macular edema. Ophthalmology 2013;120:1843-1851.

-63 Nguyen QD, Schachar RA, Nduaka CI, Sperling M, Basile AS, Klamerus KJ, et al: Doseranging evaluation of intravitreal siRNA PF04523655 for diabetic macular edema (the DEGAS study). Invest Ophthalmol Vis Sci 2012;53:7666-7674.

64 Prenner JL, RACE Study Group: The RACE Study: bevasiranib for the treatment of diabetic macular edema (abstract 5045). Assoc Res Vision Ophthalmol Annu Meet, Fort Lauderdale, October 5, 2007.

65 Krishnadev N, Forooghian F, Cukras C, Wong W, Saligan L, Chew EY, et al: Subconjunctival sirolimus in the treatment of diabetic macular edema. Graefes Arch Clin Exp Ophthalmol 2011;249:1627-1633.

-66 Dugel PU, Blumenkranz MS, Haller JA, Williams GA, Solley WA, Kleinman DM, et al: A randomized, dose-escalation study of subconjunctival and intravitreal injections of sirolimus in patients with diabetic macular edema. Ophthalmology 2012;119:124-131. 